\title{
Aprendizagem no contexto da modalidade Educação de Jovens e Adultos (EJA): uma reflexão à luz da Andragogia
}

\section{Resumo}

O presente artigo apresenta o resultado de uma investigação sobre os sentidos que assumem o processo de aprendizagem de pessoas jovens e adultas no contexto da EJA. Foi desenvolvido com a participação de gestores, professores e coordenadores pedagógicos do sistema de ensino municipal de Teresina, capital do Piaúi. Utiliza como procedimentos metodológicos para produção dos dados o questionário, a entrevista e a técnica do grupo focal. A organização e a interpretação dos dados apoiamse em Bardin (2011), Oliveira (2007) e nos princípios da Análise do Discurso. Os resultados alcançados apontam para uma concepção de aprendizagem que valoriza as experiências e os saberes dos estudantes adultos, sendo vistos como pessoas que sabem fazer suas escolhas, percebem e analisam as consequências dessas escolhas. Público que sabe o que quer da escola, por isso exige dela e dos professores um saber do quê e do como ensinar.

Palavras-chave: Andragogia; Aprendizagem; Educação de Jovens e Adultos.

\section{Francisco das Chagas Alves Rodrigues}

Mestre em Educação pela

Universidade Federal do Piauí -

UFPI. Professor do Município de

Teresina - PI.

Brasil

fcorod@bol.com.br

\section{Maria da Glória Carvalho Moura \\ Doutora em educação pela \\ Universidade Federal do Rio Grande do Norte - UFRN. \\ Professora da Universidade \\ Federal do Piauí - UFPI. \\ Brasil \\ glorinha_m@yahoo.com.br}

\section{Para citar este artigo:}

RODRIGUES, Francisco das Chagas Alves; MOURA, Maria da Glória Carvalho. Aprendizagem no contexto da modalidade Educação de Jovens e Adultos (EJA): uma reflexão à luz da Andragogia. Revista PerCursos, Florianópolis, v. 17, n.34, p. 112 - 133, maio/ago. 2016.

\section{DOI: 10.5965/1984724617342016112}

http://dx.doi.org/10.5965/1984724617342016112 


\title{
Learning in the context of Youth and Adult Education mode (EJA): reflecting the light of Andragogia
}

\begin{abstract}
This article presents the results of an investigation into the way they take the learning process of young people and adults in the context of adult education. It was developed with the participation of managers, teachers and coordinators of the municipal education system of Teresina, capital of Piauí. Used as instruments for the production of data the questionnaire, the interview and the technique of the focus group. The organization and interpretation of data are supported by Bardin (2011), Oliveira (2007) and the principles of discourse analysis, for support in Orlandi (2012). The results achieved point to a conception of learning that values the experiences and knowledge of adult learners being seen as people who know how to make their choices, realize and analyze the consequences of those choices. Audience that knows what they want from school, so it requires teachers and a knowledge of what and how to teach.
\end{abstract}

Keywords: Andragogy; Learning; Education for Youth and Adults. 


\section{Introdução}

Uma educação pública e de qualidade é pressuposto básico intrinsecamente interligado e almejado por todos, visto que uma educação pública de qualidade contribui para a aprendizagem e esta intervém de forma significativa no desenvolvimento de uma nação, por ser uma das principais vias para construção de uma sociedade mais solidária, justa e democrática.

Neste sentido, constitui-se em uma poderosa ferramenta para a mudança social, pois a educação é o elemento fundamental para o desenvolvimento pessoal e para a realização da vocação do ser humano. É considerada o caminho para formar pessoas sensíveis para as questões que afetam todos os grupos minoritários, para a prática da liberdade e para o exercício da cidadania.

A educação, também, é considerada o caminho para a mobilização social, sem a qual as mudanças não se viabilizam. No entanto, quando o objeto de discussão está centrado em Educação de Jovens e Adultos (EJA), a dinamicidade dessas duas concepções, educação pública e qualidade, na maioria das vezes são refletidas em separado, trazendo inúmeros prejuízos para a consolidação de políticas públicas para essa modalidade de ensino.

Sem dúvida, a complexidade dessas concepções tem influenciado o desenho de políticas e desafios para a EJA, uma vez que no Brasil as pesquisas voltadas para a educação do adulto, preocupando-se como o sujeito adulto aprende é incipiente, sendo que a preocupação está em comprovar que o país ainda possui milhões de pessoas jovens e adultas analfabetas ou que não concluíram o ensino fundamental (MOURA, 2012).

Nesse paradigma, para alcançar a tão sonhada qualidade na educação pública, o foco da discussão precisa se ampliar, estreitar as relações com todos os níveis e modalidades de ensino. As concepções de aprendizagem, tanto das crianças, quanto dos adultos devem ser estudadas em uma perspectiva de desenvolvimento, aprofundando a compreensão do processo de aprendizagem. Isso significa dizer que os estudos sobre educação precisam trazer abordagens de questões relacionadas com 
aspectos do desenvolvimento da aprendizagem do jovem e do adulto, na perspectiva de intervenções adaptadas às situações de aprendizagens vividas pelos aprendizes.

Partindo do princípio de que o sujeito adulto, em formação, tem sua forma própria de apreender os conhecimentos historicamente organizados, relacionando-os com os conhecimentos adquiridos durante sua história de vida, da mesma forma o pesquisador vai construindo a ciência de acordo com seu próprio método, na busca de atender às exigências epistemológicas decorrentes das teorias que as referendam (MOURA, 2012). Pretende-se, nesse estudo, voltar a atenção para um ponto complexo que merece ser refletido por ser o objeto da qualidade da educação, cuja relação existencial escapa, devido à sua complexidade, dificultando a apropriação do conhecimento e a sua descoberta: a aprendizagem de pessoas jovens e adultas.

A Constituição Federal de 1988 e a Lei de Diretrizes e Bases da Educação Nacional (LDB) n 9.394/96 regulamentam políticas voltadas para o atendimento do público jovem e adulto, que frequenta as escolas brasileiras. Dentre essas políticas têmse: as Diretrizes Curriculares Nacionais e Operacionais, material didático específico para a modalidade EJA, financiamento via Fundo de Desenvolvimento da Educação Básica e Valorização dos profissionais do Magistério (FUNDEB).

Paradoxalmente, essas políticas não conseguiram melhorar os frágeis resultados na modalidade EJA, que continua apresentando um quadro anual com altos índices de retenção e de evasão escolar, que se configuram em desafios para a EJA, principalmente no Ensino Fundamental, como consequência de vários fatores, dentre eles destacam-se as formas como a aprendizagem dessas pessoas é concebida e avaliada.

Motivados por essa realidade, faz-se uma reflexão e análise crítica sobre as concepções e os sentidos que assumem a aprendizagem dos jovens e adultos frequentadores das escolas públicas, de ensino fundamental dessa modalidade de ensino.

Atualmente, termos como excluídos, discriminados e marginalizados, geralmente estão ligados àquelas pessoas que não conseguem ou não tiveram oportunidades de aprender. Excluídos do mercado de trabalho, pois não acompanharam as inovações tecnológicas; discriminados socialmente, pois não dominaram as novas competências e 
habilidades requeridas pelo mercado; marginalizados culturalmente, por não terem apreendido a cultura letrada, os novos saberes exigidos para bem viver numa sociedade moderna e competitiva. Para obter uma vida produtiva na atualidade é obrigação de toda pessoa, jovem ou adulta, desenvolver diferentes estratégias de aprendizagem.

Deve-se aprender por ser uma exigência social em um mundo cada vez mais demandante, bem como para aquisição de saúde, lazer, trabalho ou outros bens sociais de qualidades, sem os quais não é permitido a qualquer indivíduo prescindir de conhecimentos para usufruí-los ou reivindicá-los.

O mundo dos negócios, de um modo particular, assim como o mundo moderno, de um modo geral, exige das pessoas um constante aprendizado para que elas obtenham sucesso ou pelo menos sobrevivam no mundo do trabalho, para que não se sintam marginalizadas e sem oportunidades.

As demandas sociais, as conquistas sociais, características de uma sociedade democrática e moderna, exigem do cidadão adulto o desenvolvimento de capacidades para usufruir desses direitos sociais conquistados e para o exercício da cidadania.

Uma boa educação tornou-se obrigação de todos: homens e mulheres, jovens e adultos, residentes no campo ou na cidade, sejam estes trabalhadores autônomos ou assalariados, temporários ou permanentes, patrões ou empregados, estudantes ou professores universitários. As dinâmicas da vida moderna, a subordinação de fatos locais a outros fatos globalizados exige uma atualização contínua a respeitos dos acontecimentos, requerendo uma formação ao longo da vida.

\section{Aprendizagem de pessoas jovens e adultas}

Desde a pré-história, para sua sobrevivência, o homem teve que desenvolver estratégias de aprendizagem para adequar seus conhecimentos às exigências da realidade que o circundava, fosse para produzir seus alimentos, superar a estratégia de guerra, conseguir uma parceira, garantir a permanência da raça ou se sobressair em seu espaço de trabalho. Tudo isso, no entanto, exigia esforço, tempo, reflexão, erro, 
acerto e técnicas apropriadas para sua execução. Enfim, a forma certa de aprender sempre foi o caminho para o sucesso.

Atualmente, com o desenvolvimento da tecnologia e a carência de mão de obra qualificada para o mercado de trabalho, mais do que nunca a aprendizagem é foco de estudos e pesquisas. Os estudos voltados para a aprendizagem de pessoas jovens e adultas no Brasil carecem de muitas pesquisas, haja vista o Brasil ser um país com milhões de adultos aptos para o mercado de trabalho que não sabem ler nem escrever, fato que certamente repercute negativamente para a produção nacional e macula a imagem do país no exterior. É neste contexto, que a aprendizagem assume uma página de emergência nas pesquisas em educação.

Nesse sentido, Finger e Asun (2003, p. 13) refletem que:

Nunca antes se falou tanto de aprendizagem. Não só a aprendizagem pelas crianças, mas aprendizagem de todos os membros da sociedade, unidades organizacionais, comércio, e até a sociedade no seu todo. Isso não significa que nunca assim tenha acontecido, a novidade esta no fato de tal aprendizagem ser atualmente medida, quantificada, certificada, reconhecida e ativamente promovida.

A exigência da vida moderna, com seus avanços tecnológicos e o acesso da informação a todas as pessoas e em todos os lugares instiga gestores públicos a pensarem em políticas sociais e educacionais que beneficiem toda a sociedade, mas essas conquistas não têm atingido boa parte da população, por ser analfabeta e não saber como acessar esses benefícios. É neste contexto que a aprendizagem de pessoas jovens e adultas, o conhecimento pelos profissionais da escola de como ela acontece e se processa no cotidiano da sala de aula, apresenta-se como uma pauta urgente na educação brasileira.

Para a pessoa jovem e adulta, a aprendizagem ocorre quando o conhecimento adquirido pode ser útil para sua vida. Nesse processo de aprendizagem, a imposição docente cede lugar ao diálogo e ao convencimento argumentativo, a fim de que o aluno apreenda os conhecimentos, atribuindo-lhes um novo sentido. Portanto, 
"no processo de aprendizagem só aprende verdadeiramente aquele que se apropria do aprendido, transformando-o em apreendido, podendo, por isso mesmo, reinventáIo" (MOURA, 2012, p. 08).

Vive-se em uma sociedade do conhecimento, das rápidas e excessivas informações, em que aprender é condição imprescindível para se viver bem. Das aprendizagens das pessoas depende o desenvolvimento da educação, da saúde, da economia, da política e da própria civilização. Tornou-se uma sociedade de indivíduos aprendentes. Nesta perspectiva, a prática pedagógica deve preocupar-se em desenvolver quatro aprendizagens fundamentais, que servirão de base para novos conhecimentos. A este respeito, Delors (2012, p. 90) explica que:

para poder dar resposta ao conjunto das suas missões, a educação deve organizar-se em torno de quatro aprendizagens fundamentais que, ao longo de toda a vida, serão de algum modo para cada indivíduo, os pilares do conhecimento: aprender a conhecer, isto é adquirir os instrumentos da compreensão; aprender a fazer, para poder agir sobre o meio envolvente; aprender a viver juntos, a fim de participar e cooperar com os outros em todas as atividades humanas; finalmente aprender a ser, via essencial que integra as três precedentes. É claro que estas quatro vias do saber constituem apenas uma, dado que existem entre elas múltiplos pontos de contato, de relacionamento e de permuta.

Estes saberes são fundamentais para a vida de pessoas jovens e adultas, pois o aprender a conhecer indica o interesse, o querer, a abertura para o conhecimento que verdadeiramente liberta os sujeitos da ignorância. O aprender a fazer mostra a coragem de executar, de correr riscos, de errar, mesmo na busca de acertar. 0 aprender a conviver traz o desafio da convivência que apresenta o respeito a todos e o exercício de fraternidade como caminho do entendimento, tão essenciais nesse século marcado pela violência e desrespeito aos direitos mais básicos do cidadão.

O aprender a ser envolve o papel do cidadão e a intenção de viver a educação pautada nos valores e atitudes direcionados para a vida em sociedade, partindo do sujeito individual. Os domínios aprender a ser e aprender a conviver consistem num dos 
maiores desafios para os educadores, pois atuam no campo das atitudes e valores.

As reflexões sobre aprendizagem no campo da educação de adultos foram fragilizadas pelo fato de nunca ter sido um campo intelectualmente coerente e unificado. Finger e Asun (2003, p. 14) refletem que:

Há ocasiões em que a aprendizagem é considerada apenas individual, contribuindo para o crescimento pessoal, neste caso a educação de adultos tem principal referência a psicologia humanista. Outras há em que é vista como um processo de desenvolvimento cognitivo conducente ao desenvolvimento e à competências intelectuais. Aqui a educação de adultos toma como referência a pedagogia iluminista e a teoria crítica, uma abordagem especialmente difundida na Europa. Por fim, particularmente na abordagem americana, a aprendizagem é também encarada como resolução de problemas.

A grande quantidade de teóricos que se debruçaram sobre a aprendizagem de pessoas jovens e adultas fora do Brasil aponta para uma discussão que, diferentemente da situação brasileira, pode apresentar saídas mais seguras para este grande desafio de compreender como estes sujeitos aprendem.

Diante das dificuldades ora observadas nas tentativas de contribuir para a aprendizagem de pessoas jovens e adultas, tentativas estas baseadas em metodologias nas quais os sujeitos adultos, com seus saberes, não são respeitados; seus conhecimentos prévios não são considerados no planejamento das aulas, em que os professores tentam ensinar-lhes como fazem com as crianças, razão pela qual é de extrema urgência que os professores conheçam como os estudantes adultos aprendem e qual o papel do professor nesta outra perspectiva de aprendizagem.

No Brasil, a educação de adultos foi e ainda é muito influenciada pelas ideias de Paulo Freire (1921-1997). Este, ao criticar o procedimento pedagógico que deixa o professor na condição de transmissor do conhecimento e encara o aluno como passivo da ação educativa, o que denominou de "educação bancária”, contrapõe que: 
Ao apontar as relações entre aluno e conhecimento, Freire coloca o aluno como sujeito, e não como objeto do processo educativo, afirmando sua capacidade de organizar a própria aprendizagem em situações didáticas planejadas pelo professor, num processo interativo, partindo da realidade desse aluno. (BRASIL, 2002, p. 98)

Ademais, é preciso insistir na defesa de uma educação com caráter emancipatório, libertador, dialógico, problematizador e questionador da realidade, no sentido oposto ao de uma educação para a submissão. Assim, a escola deve ser lugar de criação, de liberdade, não de imposição ou de medo. Nesse contexto, as práticas avaliativas devem ser de regular, acompanhar, orientar ao invés de classificar, selecionar, medir.

É nesta mesma linha de compreensão que as concepções socioconstrutivistas defendem o conhecimento, não como "algo situado fora do indivíduo, a ser adquirido por meio da cópia do real, tampouco algo que o indivíduo constrói independente da realidade exterior, dos demais indivíduos e de suas próprias capacidades pessoais" (BRASIL, 2002, p. 99), mas como respeito à história de vida, dos conhecimentos prévios das pessoas jovens e adultas assumidas de maneira fundamental, dada a sua importância na construção das aprendizagens.

Foi neste contexto que, a partir da década de 1970, preocupados com os rumos que tomava a educação de adultos, alguns teóricos apresentaram alternativas à aprendizagem direcionada, centrada no professor, característica da pedagogia, posicionando-se a favor da aprendizagem facilitada, centrada no aluno. Nela, a aprendizagem é compartilhada entre professor e aluno, respeitando-se saberes, vivências e experiências destes sujeitos. Essa realidade se refere ao modelo chamado andragógico, de aprendizagem de pessoas jovens e adultas.

Esse modelo surgiu incialmente como antagônico ao pedagógico, mas, posteriormente, como um contínuo ou complemento deste (DEAQUINO, 2007). A andragogia é apresentada como "a ciência que procura entender como ocorre a aprendizagem na fase adulta do ser humano em todos os âmbitos: psicológicos, biológicos e sociais" (MOURA, 2012, p. 03). 
Apesar de somente a partir do ano de 1950, o Educador Malcolm Knowles (19021987) ter começado a organizar uma teoria de aprendizagem de pessoas jovens e adultas, as reflexões propostas foram resultados de discussões e debates que há muito tempo ocupam espaços em congressos e seminários da área, embora esse conhecimento ainda não seja da compreensão de muitos educadores brasileiros, que lidam com a modalidade EJA.

Na década de 1970, quando ainda era (ou já era) muito forte a ideia de que a aprendizagem se dava de forma direcionada, ou seja, em que existia a figura de um professor que se encarregava de direcionar todos os passos do processo de aprendizagem dos alunos, Knowles e Carl Rogers (1902-1987), além de outros educadores, começaram a promover a ideia de uma aprendizagem centrada no aprendiz ou facilitada, que eles denominaram de aprendizagem auto direcionada. Em ambos, a experiência do aprendiz assume lugar de destaque na construção da aprendizagem.

A aprendizagem é facilitada quando o aluno participa de maneira responsável no processo, já que este aluno escolhe a própria direção e ajuda a descobrir os seus próprios recursos. Nessa perspectiva, o papel do professor é centrado “[...] principalmente no ambiente de aprendizagem, onde tem de criar as condições ótimas para o autodesenvolvimento" (FINGER; ASUN, 2003, p. 64).

A figura de um facilitador é crucial para o contexto da aprendizagem do adulto, visto que é responsável por criar um clima de aprendizagem, ajudando os educandos adultos a clarificarem suas interpretações, a ampliarem o conhecimento e a se desenvolverem. Assim, acredita-se que a pessoa não cresce, não aprende, se a experiência de aprendizagem não for significativa.

A psicologia humanista popularizada por Knowles foi responsável pela transposição desta para o campo da educação de adultos, na década de 1970. Autor de inúmeros livros e artigos voltados para a temática, Knowles é considerado o "apóstolo da andragogia" (FINGER; ASÚN, 2003). Definida inicialmente como "a arte e a ciência de ensinar os adultos a aprender”, essa definição inicial, hoje, evoluída, “[...] apresenta-se, atualmente, como uma alternativa à pedagogia e refere-se à educação centrada no 
aprendiz para pessoas de todas as idades" (DEAQUINO, 2007, p. 11).

A responsabilidade pela aprendizagem de pessoas adultas é compartilhada, fazendo com que o aluno se sinta corresponsável pela sua própria aprendizagem, conquistando mais autonomia e independência. Então, a prática docente deve priorizar o processo de aprendizagem, indo além dos conteúdos, "nesse sentido, o objeto da educação de jovens e adultos não é tanto ministrar o ensino, mas assegurar uma formação" (MOURA, 2012, p. 05).

Neste contexto, as experiências são, por um lado, fonte de aprendizagem, principalmente quando se reflete sobre elas; por outro, são o resultado do processo de aprendizagem, tornando-as mais significativas. No modelo de aprendizagem auto direcionada,

[...] o objetivo da educação tem um foco maior no processo (desenvolvimento de pensamento crítico, crescimento como pessoa e cidadão) do que no conteúdo [...]. A grande contribuição [...] é criar oportunidade para que eles decidam onde envidar seus esforços a fim de aprender aquilo que possa ajudá-los a resolver os problemas que enfrentam na vida pessoal e profissional, bem como para preparálos adequadamente para aquilo que desejam ser, em um futuro próximo. (DEAQUINO, 2007, p. 24)

O professor, como facilitador da aprendizagem, assume o papel de colaborador no desenvolvimento da consciência cidadã e participativa do adulto, tornando-o livre, responsável e apto para resolver seus problemas cotidianos, decidir seus próprios caminhos.

A partir dos anos de 1970, a abordagem de aprendizagem transformadora foi foco de estudos e pesquisas, a exemplo do pesquisador Jack Mezirow (1923- 2014) que formulou reflexões acerca da aprendizagem referida como "transformação de perspectiva". Nela, os aprendizes alcançam elevados níveis de conhecimento sobre si, sobre os outros e sobre o mundo. São capazes de questionar suas realidades a fim de mudá-las de modo reflexivo e consciente, "[...] o facilitador mais eficaz é aquele que estimula os adultos a considerar de forma racional e cuidadosa as perspectivas e 
interpretação do mundo que diferem das que eles já têm, sem fazer esses adultos se sentirem enganados e ameaçados" (KNOWLES; HOLTON III; SWANSON, 2009, p. 111).

De acordo com a abordagem já mencionada, “[...] os aprendizes são incentivados a desafiar, defender e explicar suas crenças, a avaliar suas evidências e justificativas e a julgar argumentos para atingir o objetivo máximo de crescimento pessoal, independência e pensamento crítico" (DEAQUINO, 2007, p. 25).

As perspectivas que os indivíduos traziam de seu passado, muitas já consolidadas e estabelecidas, são revisitadas pela reflexão e redefinidas em novas intepretações, novos conceitos e comportamentos. O desafio consiste no confronto dessas perspectivas passadas e atuais, cabendo ao facilitador considerá-las no processo de aprendizagem de adultos.

A aprendizagem de fato significativa ocorre nas pessoas jovens e adultas quando a referida transformação de perspectiva ocorre. Para tanto, o diálogo é imprescindível na ação educativa, pressupondo-se que os atores se relacionem de modo horizontal; dito isto, "é neste contexto de aprendizagem comunicativa, através do discurso racional, que a reflexão crítica pode desenvolver todo o seu potencial e ajudar o indivíduo a questionar suas próprias premissas básicas. E, ao fazê-lo, ajudá-lo a transformar as suas perspectivas" (FINGER; ASUN, 2003, p. 57).

Assim como no caso da aprendizagem auto direcionada, a contribuição da aprendizagem transformadora consiste em ajudar os adultos aprendizes a vencer obstáculos no seu processo de crescimento pessoal e profissional. Diferencia-se da primeira abordagem por incentivar o desenvolvimento do pensamento crítico do aprendiz.

Inspirado no trabalho de Dewey, na década de 1980, David Kolb (1939) desenvolveu o "ciclo da aprendizagem vivencial", em que há o envolvimento do aprendiz e seu aprendizado no aprofundamento do conhecimento pela experiência, reflexão, experimentação e aplicação. As competências advindas da junção desses momentos estimulam o crescimento pessoal e profissional do aprendiz, resultando numa relevante contribuição à educação de adultos. No entender de Kolb, “[...] a 
aprendizagem de adultos seria mais eficaz [...] sempre que o objeto da aprendizagem fosse mais direta e profundamente vivenciado do que quando ele fosse simplesmente recebido de maneira passiva" (DEAQUINO, 2007, p. 26).

Essa concepção de aprendizagem é caracterizada por seis aspectos,

a) Aprendizagem tem sempre de ser vista em termos de processo e não em termos de resultados [...]. b) Aprendizagem é um processo experiencial, dado que apenas progride através de experiências contínuas [...]. c) Ao longo do processo experiencial há quatro capacidades ou processos de adaptação ao mundo: (1) a capacidade de ter experiências concretas; (2) a capacidade de fazer observações reflexivas; (3) a capacidade de fazer conceptualizações abstratas; (4) a capacidade de fazer experimentações ativas [...]. d) A aprendizagem é, assim, uma adaptação holística ao mundo [...]. e) aprender implica, portanto, uma série de transações entre a pessoa e o seu ambiente [...]. f) em resultado desta transação, a aprendizagem conduz à criação de conhecimento. (FINGER; ASUN, 2003, p. 46, grifos do autor)

A aprendizagem é resultante do somatório das experiências vividas pelos indivíduos, ocorrendo num processo contínuo. Não ocorre apenas no nível abstrato ou concreto, mas se dá como decorrência de várias capacidades. A aprendizagem acontece num contínuo de adaptações, trocas entre pessoas e ambientes. Enfim, o resultado de diferentes saberes conduz ao conhecimento.

Os quatro passos denominados de modelo de Kolb, presentes no terceiro aspecto que caracteriza a aprendizagem: capacidade de ter experiência concreta, capacidade de fazer observações reflexivas, capacidade de fazer conceptualizações abstratas e capacidade de fazer experimentações ativas atende positivamente à aprendizagem do adulto. Além disso, “[...] representa um maior envolvimento do aprendiz com seu aprendizado em termos globais, ou seja, um processamento mais profundo de conhecimento e habilidades por meio da experiência, reflexão, experimentação e aplicação" (DEAQUINO, 2007, p. 27).

Essa aprendizagem implica uma série de relações e trocas entre as pessoas e o ambiente que as circunda. Nessas relações se dá a experiência, que se configura em 
outro elemento importante para a aprendizagem de pessoas jovens e adultas.

Assim, como a aprendizagem transformadora de Mazirow, a aprendizagem vivencial de Kolb provoca no aprendiz a capacidade de problematizar a sua realidade, modificando seu pensar e agir arraigados. Nesse sentido, a aprendizagem é vista como “interação entre conteúdo e experiência, em que um transforma o outro" (KNOWLES; HOLTON III; SWANSON, 2009, p. 213), em que o aprendiz de uma maneira interativa torna-se capaz de discernir, adaptar e ressignificar o conhecimento em benefício próprio.

A compreensão por parte dos educadores que atuam na modalidade EJA, do modo como ocorrem os processos de aprendizagem de pessoas jovens e adultas é de fundamental importância para que eles possam pensar práticas mais eficazes para avaliá-los. Práticas avaliativas democráticas, em que os educandos estejam conscientes de seus objetivos, deixam de ser temidas e passam a ser encaradas como práticas de inclusão e emancipação destes sujeitos.

\section{Metodologia}

A pesquisa de abordagem qualitativa do tipo descritiva foi realizada em duas escolas localizadas em bairros da periferia da cidade de Teresina, uma na Zona Norte e uma na Zona Sudeste. Para tanto, foi selecionado um grupo de 14 professores, lotados em duas escolas que atuam em turmas dos anos finais do ensino fundamental.

A escolha se deu devido às escolas ofertarem EJA há mais de uma década e por terem no corpo docente e administrativo profissionais com bastante experiência nesta modalidade de ensino. São as duas escolas com maior número de alunos matriculados na EJA, de um total de 45 escolas, funcionando a mais de uma década.

Para os fins de acesso às informações empíricas, utilizou-se como instrumentos o questionário e a entrevista. O primeiro, com a finalidade de delinear o perfil dos participantes da pesquisa referente a sua situação pessoal e profissional, foi aplicado a todos os professores, coordenadores pedagógicos e gestores das escolas pesquisadas. Já a entrevista foi aplicada através da técnica de grupo focal, constituído por educadores 
das duas escolas selecionadas. O grupo focal foi realizado em três sessões de duas horas cada, sendo realizado pré-teste com outros profissionais que atuam na mesma escola do pesquisador. O roteiro era composto de oito questões abertas, cujo teor mantinha coerência com os objetivos da pesquisa.

Essa técnica consiste em selecionar participantes, obedecendo a critérios elencados pelo pesquisador conforme o problema em estudo, em que os participantes com características comuns interagem entre si, estimulados pelo tema a ser abordado (BARBOUR, 2009). Selecionar pessoas com diferentes opiniões em relação ao tema a ser discutido é um desses critérios, pois o objetivo não é apenas obter dados quantitativos, mas o que é fundamental para o estudo são as concepções e percepções de cada sujeito sobre o foco do objeto investigado.

Para compor o grupo focal foi convidado um representante de cada componente curricular, totalizando oito professores: um professor de cada área (Língua Portuguesa, Matemática, História, Geografia, Ciências, Artes e Língua Estrangeira - Inglês). A participação na pesquisa se deu por livre adesão e definiu-se como critério de inclusão: ser professor de escola municipal e trabalhar com o segundo segmento do ensino fundamental na modalidade EJA. A escolha desse segmento justificou-se pelo fato de que poucas escolas do município de Teresina ofertam esse segmento na modalidade EJA.

\section{Aprendizagem no contexto da EJA: resultados e discussões da pesquisa}

Os dados produzidos pelos participantes que constituíram o grupo focal foram trabalhados e organizados em dois eixos temáticos (01-Superar desafios; 02Tranformação significativa). Para analisá-los, fez-se uso da Análise do Discurso (AD) por acreditar-se que permitirá a compreensão dos sentidos e significados expressos nas contribuições dos participantes (ORLANDI, 2005).

Para a proteção das identidades dos participantes, conforme a ética da pesquisa, estes foram identificados por pseudônimos, usando os nomes de pedras preciosas: Esmeralda, Cristal, Diamante, Topázio, Quartzo Ágata, Opala, Safira. 
Assim, apresentam-se algumas falas, de onde foi possível identificar a concepção de aprendizagem presente na prática e no discurso dos professores. No Eixo Temático 01Superar desafios ficou evidente a necessidade de uma maior compreensão, pelos professores, sobre a Andragogia, ciência que se preocupa com o ensino e a aprendizagem de pessoas jovens e adultas, sem desconsiderar os preceitos das outras ciências, principalmente da Pedagogia. Seguem as falas dos participantes:

1- Mudança de atitude diante de um desafio. A aprendizagem proporciona meios para superar esse desafio. Aprendizagem é armar nossos alunos de alguma forma. Diante de novos desafios, de novas propostas, ele ter condições de se comportar diferente. Então, eu vou munir ele diante dos desafios da vida, assim ele possa enfrentar esses desafios. (ESMERALDA)

2- Mudança de comportamento. Aprendizagem é algo que você incorpora e passa a utilizar. É uma ferramenta. Então eu tenho uma chave; é preciso abrir alguma coisa com aquela chave. Se eu aprendi, eu uso aquela chave... É mudar a maneira de ser, de agir, de pensar, de se comportar de tudo. (CRISTAL)

3- Mudança de comportamento, de atitude. Aprendizagem... Ao aluno já consegue resolver problemas só, sem ajuda do professor, porque ele assimilou os conteúdos, então ele aprendeu. (DIAMANTE)

4- É a mudança de comportamento e ideias da realidade dos alunos. É fazê-los críticos... É reconhecer alguma coisa, aprender, pensar sobre aquilo que ele está observando, isso é aprender... No momento que você identifica alguma coisa e você pode processar isso em termo de crítica, de valores do que é certo, do que é errado, na hora que eu percebo alguém com capacidade de ser crítico nas suas ações eu percebo que aprendeu. (TOPÁZIO)

Provocados sobre a compreensão de aprendizagem, os interlocutores foram unânimes em afirmar que esta se apresenta como elemento essencial de transformação, visto que, em todos os trechos, as falas remetem para o enfrentamento de desafios na perspectiva de superação. Veja-se: [...] ter condições de se comportar diferente (ESMERALDA); É mudar a maneira de ser, de agir, de pensar, de se comportar [...] (CRISTAL); Mudança de comportamento, de atitude [...] (DIAMANTE) e [...] capacidade de ser crítico nas suas ações [...] (TOPÁZIO).

O posicionamento de Esmeralda não deixa dúvida de que o aluno da EJA 
demonstra que realmente aprendeu quando se sente capaz de fazer uso do conhecimento apreendido para o enfrentamento de questões cotidianas, presentes no seu dia a dia. Assim, "os sujeitos jovens e adultos, na sua maioria, não aprendem por aprender, mas para se tornarem capazes de enfrentar satisfatoriamente os desafios que a vida lhes oferece" (MOURA, 2012, p. 06).

Cristal, trecho (2), externa a compreensão de aprendizagem quando o aluno demonstra que é capaz de fazer uso do conhecimento aprendido em quaisquer situações que se apresentem, seja nas suas relações interpessoais, na forma de ver o mundo e de se ver diante dele. Razão pela qual o professor, como mediador do processo de aprendizagem deve provocá-los com atividades desafiadoras, relacionando os conhecimentos que precisam aprender com o conhecimento que trazem de sua prática cotidiana, que façam a diferença na vida do estudante, pois "os jovens e adultos aprendem resolvendo problemas ligados à realidade, se os problemas não tiverem relação com a realidade, se não forem vivenciados, perdem o interesse" (MOURA, 2012, p. 08).

Diamante reforça o posicionamento de Esmeralda e Cristal ao afirmar que a aprendizagem ocorre quando o estudante apresenta "[...] Mudança de comportamento, de atitude", revelando que a aprendizagem contribui para que ele se torne um sujeito autônomo e, que essa autonomia faz com que adquira a segurança que a aprendizagem confere. Dessa forma, compete ao professor “[...] engajar-se no processo de mútua investigação com os alunos e não apenas transmitir-lhes conhecimentos e depois avaliá-los" (MOURA, 2012, p. 11).

Para Topázio, trecho (4), a aprendizagem se configura quando o aluno demonstra a "capacidade de ser crítico nas suas ações". Esta criticidade tem visibilidade quando interfere com responsabilidade nas realidades do seu entorno, na perspectiva de transformação. Dessa forma, a aprendizagem "estimula o desenvolvimento do pensamento crítico, e não da mera aceitação de práticas consagradas [...]" (DEAQUINO, 2007, p. 28). Como exemplos, estão os mitos fortemente consolidados nas instituições escolares. 
Partindo do pressuposto de que é pelo intermédio das experiências, das emoções e da reflexão que o indivíduo aprende, sendo esta última essencial para o processo de aprendizagem, da transformação seguem-se as falas dos participantes reunidas no Eixo Temático 02- Transformação significativa:

1- Transformações sociais, visão de mundo. Aprendizagem está relacionada com a experiência de vida, de mundo, com teoria e prática. (QUARTZO)

2- Um processo que se dá continuamente. É aprender qualquer coisa, em qualquer lugar, em qualquer situação. Digamos... Na sala de aula, o professor ministra um conteúdo, eu presto atenção e consigo aprender... Até o que minha cabeça deu para eu conseguir aprender. Na rua, eu aprendo sobre atividade bancária, eu vejo alguém construindo um muro e eu aprendo... Isso é aprender. (ÁGATA)

3- Aprender é um processo de assimilação, de aquisição do conhecimento, de juntar a teoria que foi passada para mim com a prática que eu vivo no meu cotidiano, distinguir o que foi posto, o que foi colocado em determinada situação. Acontece em vários âmbitos, não só na escola. (OPALA)

4- Mudança, transformação, conhecimento. Aprender é algo tão significativo que ao mesmo tempo pode significar o novo e pode também significar o abandono de certos atos antigos, pois quando aprendemos, fazemos reorganizações de pensamentos, de atitudes; é algo que faz parte do ser humano. Aprendemos até quando achamos que não estamos fazendo isso... (SAFIRA)

O Eixo Temático 02 reúne informações significativas que apontam para uma compreensão de aprendizagem resultante da "experiência de vida" (QUARTZO), "que se dá continuamente" (ÁGATA), "fruto da teoria e da prática" (OPALA E QUARTZO), "transformação [...] algo significativo" (SAFIRA).

Quartzo, trecho (1), demonstra respeito pelos conhecimentos trazidos pelos estudantes de EJA para a sala de aula, ao enfatizar suas experiências. Aceitando a visão de mundo do estudante, evidencia que atua como um facilitador da aprendizagem, considerando que esta acontece em todos os contextos e espaços do sujeito em formação e é sistematizada na escola, instituição responsável pela comprovação de sua escolaridade. No contexto das escolas de pessoas jovens e adultas, a 
experiência assume papel central diante do desafio de aprender. (KNOWLES; HOLTON III; SWANSON, 2009, p. 213).

Sabe-se que as pessoas jovens e adultas são motivadas a permanecer na escola quando percebem que suas necessidades e interesses serão satisfeitos, atendendo aos objetivos de alcance imediato que possam transformar suas vidas. Nesse sentido, “[...] para iniciar a organização de uma proposta de aprendizagem destinada a esse público, deve-se considerar que a experiência se constitui a mais rica fonte para o jovem e adulto aprender" (MOURA, 2012, p. 11). Isso significa dizer que os elementos que compõem as vivências do estudante, têm relação direta com o contexto em que atua, se tornando um elemento indispensável para a aprendizagem.

Ágata, trecho (2), evidencia na sua fala que a aprendizagem é "um processo contínuo. É aprender qualquer coisa, em qualquer lugar, em qualquer situação [...]", assumindo que a aprendizagem se dá, também, de maneira informal, em situações que não estão veiculadas diretamente à escola. Contudo, não se deve esquecer que embora aconteça em outros espaços, necessita da escola para consolidá-la. Essas informações são significativas, devendo ser valorizadas. Opala, trecho (3), traz para a discussão a relação teoria e prática, reforçando o valor da experiência na construção do conhecimento dos estudantes da modalidade EJA.

Para Safira, trecho (4), a aprendizagem significa: “Mudança, transformação, conhecimento. Aprender é algo [...] significativo [...]". Revela que aprender implica reorganizar o pensamento, na medida em que se consegue estabelecer relações entre os conteúdos escolares e os conhecimentos experienciais, atendendo às expectativas dos estudantes jovens e adultos, provocando mudanças imediatas em suas vidas, no âmbito pessoal e profissional.

Nesta perspectiva de aprendizagem, a educação assumiria o papel de guiar os aprendizes para uma transformação pessoal em termos intelectuais e, por conseguinte, segundo DeAquino (2007, p. 24), “mudá-los, ou seja, fazê-los crescer e amadurecer para que se tornassem pessoas completas por meio de uma reflexão crítica sobre as suposições, crenças e valores próprios”. 


\section{Conclusão}

Com relação à aprendizagem na EJA, os participantes entendem que esta se consolida quando os estudantes se apresentam como capazes de resolver os seus problemas e demonstram criticidade em suas ações. Essa concepção está muito ligada à experiência do estudante, aos seus conhecimentos prévios, seus saberes vivenciais, conforme preceitua a andragogia.

Para os professores pesquisados, uma aprendizagem significativa no contexto da EJA é aquela que transforma o sujeito, ou seja, os saberes ensinados são reconstruídos pelos educadores e educandos e, a partir dessa reconstrução, tornam-se autônomos, emancipados, questionadores e críticos. Enfim, capazes de superar os desafios comuns à vida de pessoas jovens e adultas em processo de constante crescimento e sempre abertos a novos saberes.

Essa realidade reforça o valor da experiência na construção do conhecimento dos estudantes da modalidade EJA. A compreensão por parte dos educadores que atuam nesta modalidade de como ocorrem os processos de aprendizagem de pessoas jovens e adultas é de fundamental importância para que estes possam pensar em práticas mais eficazes. Projetos pensados coletivamente, incluindo os estudantes, práticas avaliativas democráticas são ações que contribuem para uma aprendizagem significativa e duradoura.

Nesta perspectiva, a figura de um facilitador é crucial para o contexto da aprendizagem do adulto, sendo responsável por criar um clima de confiança, no auxílio aos estudantes para clarificar suas interpretações, ajudando-os a crescer e a se desenvolverem com mais liberdade e autonomia frente ao conhecimento. O papel desse facilitador centra-se principalmente no ambiente de aprendizagem, no qual cria condições propícias para que esta aconteça. Assim, o adulto passa a ser visto como agente e não mais como objeto. Educador e educandos fazem parte do processo ensinoaprendizagem numa concepção mais colaborativa do saber, do saber fazer, do saber ser e conviver. 


\section{Referências}

BARBOUR, Rosaline. Grupos focais. Porto Alegre: Artmed, 2009.

BARDIN, Laurence. Análise de conteúdo. São Paulo, Edições 70: Brasil, 2011.

BRASIL. Ministério da Educação. Resolução $\mathbf{N}^{\circ}$ 1, de 15 de fevereiro de 2007. Disponível em: <https:// portal. mec.gov.br/seb/arquivos/pdf/Fundebef/fatpond_fundeb_07 PDF.> Acessado em 29/03/2007.

BRASIL. Ministério da Educação. Secretaria de Educação Fundamental. Proposta Curricular para a educação de jovens e adultos: segundo segmento do ensino fundamental: 2002.

DEAQUINO, Eira de; TASSO, Carlos.. Como aprender: Andragogia e as habilidades de aprendizagem. São Paulo: Pearson Prentice Hall, 2007.

DELORS, Jacques. (Org.). Educação um tesouro a descobrir - Relatório para a Unesco da Comissão Internacional sobre Educação para o Século XXI. 7. ed. São Paulo: Cortez, 2012.

FINGER, Mathias.; ASÚN, José Manuel. A educação de adultos numa encruzilhada: aprender a nossa saída. Porto: Porto Editora, 2003.

KNOWLES, Malcolm S.; HOLTON, Elwood F.; SWANSON, Richard A. Aprendizagem de resultados: uma abordagem prática para aumentar a efetividade da educação corporativa. 2. ed. Rio de Janeiro: Campus/Elsevier, 2009.

MOURA, Maria da Glória Carvalho. Contributos da andragogia para o estudo da aprendizagem de pessoas jovens e adultas. 2012. Mimeografado.

OLIVEIRA, Maria Marly de. Como fazer pesquisa qualitativa. Petrópolis, RJ: Vozes, 2007.

ORLANDI, Eni Puccinelli. Análise de discurso: princípios e procedimentos. 5. ed. Campinas, SP: Pontes, 2005. 
Aprendizagem no contexto da modalidade Educação de Jovens e Adultos (EJA): uma reflexão à luz da

Francisco das Chagas Alves Rodrigue, Maria da Glória Carvalho Moura

Recebido em: 09/11/2015 Aprovado em: 09/09/2016

Universidade do Estado de Santa Catarina - UDESC Centro de Ciências Humanas e da Educação - FAED

Revista PerCursos

Volume 17 - Número 34 - Ano 2016 revistapercursos@gmail.com 